\title{
EFEITO RESIDUAL DO ADUBO APLICADO NA SOJA (Glycine max L. Merrill) SOBRE A CANA-DE-AÇÚCAR (Saccharum spp.) ${ }^{1}$
}

\author{
H.A.A. MASCARENHAS ${ }^{2}$ : A.A. COSTA; R.T. TANAKA²; E.J. AMBROSANO ${ }^{2}$ \\ Instituto Agronómico, Caixa Postal 28, CEP: 13001-920, Campinas, SP \\ F.V. ROSA; V.F. COSTA \\ Nova Aliança-Agricola e Comercial Lida, C.P. 178, CEP: 14001-920, São Joaquim da Barra, SP
}

RESUMO: Foi conduzido na Fazenda Nova Aliança no município de Sales de Oliveira, SP em latossolo roxo distr6fico um experimento com 14 tratamentos para verificar o aproveitamento pela cana, do efeito residual do adubo aplicado na soja e vice-versa. $O$ delineamento experimental foi de blocos ao acaso com quatro repetiçōes. Os resultados mostraram que cana apenas aproveitou o efeito residual quando as doses de fertilizantes foram altas. Descritores: soja, cana, adubação, efeito residual.

\section{RESIDUAL EFFECT OF FERTILIZER APPLIED TO SOYBEAN ON SUGARCANE YIELD}

ABSTRACT: An experiment was installed on a dark red latosol in the County of Sales de Oliveira, SP, to verify the residual effect of fertilizer applied to soybean on the sugarcane yield and vice versa. A randomized block design with four replications was utilized. The results showed that sugarcane responded to residual fertilization only at high fertilizer doses.

Key Words: soybeans, sugarcane, fertilization, residual effect.

\section{INTRODUÇÃO}

A rotação de culturas é uma prática agrícola que consiste em alternar no mesmo terreno, diferentes culturas em uma seqüência de acordo com um plano definido (MIYASAKA, 1983).

Espécies e variedades diferem na eficiência com que utilizam os elementos absorvidos no processo de formação da colheita. Há diferenças varietais na capacidade de extrair elementos do solo e de responder a adubação (BATAGLIA et al. 1977).

Atualmente no Brasil, os produtores que utilizam a rotação de culturas vem obtendo resultados favoráveis e com isso, esta prática tem aumentado ano a ano.

Esta utilização mais intensa do solo, parece estar condicionada a razão de ordem econômica, a necessidade de produções cada vez maiores de alimentos e a sustentabilidade do sistema agrícola.
Cada espécie vegetal modificando o ambiente por sua seletividade na absorção de nutrientes, nas excreções radiculares e na brota da rizosfera, alteram o $\mathrm{pH}$ do solo, a absorção, a transpiração da água e o retorno de restos vegetais de modo que, a cada cultivo apresentam-se como um ecossistema diferente (PRIMAVESI, 1982).

Experimentação de rotação com adubos verdes em condições tropicais e subtropicais tem demonstrado aumento na produtividade dos cereais, oleaginosas e leguminosas. Uma das razões desse incremento é o balanço favorável do nitrogênio: no caso de leguminosas, estas em associações simbióticas com as bactérias formam nódulos $\mathrm{e}$ fixam aquele elemento do ar que, posteriormente, com a decomposição da fitomassa se mineraliza (MASCARENHAS et al. 1984).

$\mathrm{Na}$ produção de $50 \mathrm{~kg}$ de nitrogênio mineral consome-se energia equivalente a 80 litros de gasolina. Plantas das famílias leguminosas são as que mais fixam o nitrogênio por unidade de

\footnotetext{
' Trabalho realizado com o apoio financeiro da Nova Aliança Agrícola e Comercial Ltda. e apresentado na XXI Reunião Brasileira de Fertilidade do Solo e Nutriçăo de Plantas, realizada em Petrolina(PE), no período de 28/08 a 02/09/94.

${ }^{2}$ Bolsista do CNPq.
} 
área, além de produzirem alimentos e fibras (ROHWEDER et al. 1977). Considerando a atual crise energética e financeira nacional, esta reflete-se sobre os fertilizantes nitrogenados, com diretas implicações nos custos dos produtos agrícolas (MASCARENHAS et al. 1977).

A soja (Glycine max (L.) Merrill) é planta que fixa o nitrogênio atmosférico mediante simbiose com a bactéria Bradyrhizobium japonicum. Esta característica possibilita à leguminosa, quando a sua semente é inoculada com a bactéria, uma situação de independência de adubação para suprir as exigências em nitrogênio (MASCARENHAS et al. 1977), o mesmo não ocorrendo com a cana de açúcar (Saccharum spp.), gramínea que reage acentuadamente à aplicação do nitrogênio mineral (ESPIRONELO et al. 1987).

A cultura do milho ou algodão, em sucessão à soja aproveitam de forma eficiente o resíduo do adubo da leguminosa e ambas dispensam a aplicação de nitrogênio mineral em cobertura (MASCARENHAS, et al. 1984).

Durante o período de pousio da gleba destinada ao cultivo consecutivo da cana de açúcar (outubro a março) é possível cultivar-se a soja. Essa prática tem a vantagem de: não necessitar de novas fronteiras agrícolas, ou o deslocamento de outras culturas de grãos; minimizar a erosão pela presença de cobertura viva durante a estação chuvosa; empregar a mão de obra durante a entressafra da cana; obter renda nesse período; diminuir o custo da implantação de cana seja pelo menor preparo de solo exigido, seja pela maior disponibilidade de $\mathrm{N}$ fixado pela soja.

$O$ objetivo deste trabalho foi verificar se as doses crescentes de adubação em soja poderia dispensar a da cana em sucessão a essa leguminosa.

\section{MATERIAL E MÉTODOS}

Na Fazenda Nova Aliança, em Sales de Oliveira, SP num Latossolo Roxo distrófico foi conduzido nos anos agrícolas de 1983/85 um experimento de sucessão soja-cana. A análise química do solo (método do ácido sulfúrico) efetuiada após a aplicação de $3 \mathrm{t} / \mathrm{ha}$ de calcário dolomítico mostrou os seguintes resultados: $\mathrm{pH}$ 6,5 , matéria orgânica $2,0 \%, P=7,1 \mathrm{ppm}, \mathrm{K}=31$ ppm, Ca e $\mathrm{Mg}$ respectivamente de 1,76 e 0,72 meq/100 ml. Esta gleba havia sido cultivada com cana de açúcar para produção de mudas.
O delineamento experimental utilizado foi de blocos ao acaso, com quatro repetições. Os 14 tratamentos consistiram de:

(1) alqueive e cana sem adubo;

(2) soja sem adubo e cana sem adubo;

(3) Soja com adubo (0-42-30) e cana sem adubo;

(4) soja com adubo (0-84-60) e cana sem adubo;

(5) soja com adubo (0-126-90) e cana sem adubo;

(6) soja com adubo (0-168-120) e cana sem adubo;

(7) soja com adubo (0-210-150) e cana sem adubo;

(8) alqueive e cana com adubo (16-80-80);

(9) soja sem adubo e cana com adubo (16-80-80);

(10) soja com adubo (0-42-30) e cana com adubo (16-80-80);

(11) soja com adubo (0-84-60) e cana com adubo (16-80-80);

(12) soja com adubo (0-126-90) e cana com adubo (16-80-80);

(13) soja com adubo (0-168-120) e cana com adubo (16-80-80) e

(14) soja com adubo (0-210-150) e cana com adubo (16-80-80).

Quatro meses após o brotamento da cana, foi feita em todos os tratamentos, adubação em cobertura na dose de $40 \mathrm{~kg} / \mathrm{ha}$ de $\mathrm{N}$ na forma de sulfato de amônio. Portanto, os primeiros sete tratamentos receberam no total, $40 \mathrm{~kg} / \mathrm{ha}$ de $\mathrm{N}$ mineral, enquanto os demais receberam 56 .

A parcela da soja consistiu de 12 linhas de 10 metros espaçadas entre si de $0,60 \mathrm{~m}$. A soja 'IAC-Foscarin-31' foi semeada em outubro 1983. Um mês após a germinação foi feito $o$ desbaste deixando-se 15 plantas por metro linear. $\mathrm{Na}$ época do florescimento foram amostradas 30 folhas por parcela, para verificar o estado nutricional das plantas.

A colheita foi efetuada no início de março colhendo as quatro linhas centrais, deixando um metro de cada extremidade.

Em seguida foi plantada (sulcos de 0,25 $m$ e profundidade de $0,40 \mathrm{~m}$ ) a cana cultivar NA56-79 nas parcelas de cinco linhas de $10 \mathrm{~m}$ espaçadas entre si de $1,40 \mathrm{~m}$. Nove meses após o plantio foi feita para análise química, amostragem de 15 folhas de cana por parcela, as terceiras do ápice, excluindo a nervura. As amostras das folhas das duas culturas foram lavadas com água destilada e secas durante três dias, em estufa a temperatura de $60^{\circ} \mathrm{C}$, moídas e em seguida analisadas quanto aos teores de macronutrientes, conforme a metodologia de BATAGLIA et al. (1983). 


\section{RESULTADOS E DISCUSSÃo}

Houve um normal crescimento das plantas de soja na fase vegetativa devido a quantidades e frequências adequadas de precipitações pluviais. No início de florescimento houve dez dias de veranico, comprometendo o pegamento de vagens, resultando num coeficiente de variação alto. Conforme ARRUDA et al. (1976), o estádio crítico da soja quanto à

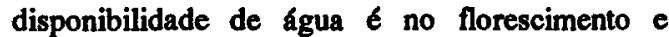
frutificação. Embora não tenha havido diferenças significativas entre os tratamentos adubados, observa-se que onde não foi feita a adubação, houve uma maior produção de soja (TABELA 1). Verificando as analises de folhas (TABELA 2), nota-se que os teores de fósforo e potássio estão em quantidades adequadas (OHLROGGE e KAMPRATH, 1968). MASCARENHAS et al. (1977) também mostraram que o cultivo da soja após o do milho e do algodão, adubados adequadamente, aproveitou eficientemente o efeito residual não necessitando de quantidades extras de nutrientes.

TABELA 1 - Produtividades de soja em função da sua adubação e de cana de açúcar em função do efeito residual da adubação de soja, e direto da adubação da cana.

\begin{tabular}{|c|c|c|c|c|c|c|c|}
\hline \multicolumn{3}{|c|}{ Adubação da soja } & \multirow{3}{*}{$\begin{array}{c}\begin{array}{c}\text { Soja } \\
1983 / 84\end{array} \\
\mathrm{~kg} / \mathrm{ha}\end{array}$} & \multicolumn{3}{|c|}{ Adubação da cana de açúcar } & \multirow{2}{*}{$\begin{array}{c}\text { Cana } \\
1984 / 85 \\
\end{array}$} \\
\hline $\mathbf{N}-$ & $-\mathrm{P}_{2} \mathrm{O}_{5}$ & $-\mathrm{K}_{2} \mathrm{O}$ & & N - & $-\mathrm{P}_{2} \mathrm{O}_{5}$ & $-\mathbf{K}_{2} \mathrm{O}$ & \\
\hline \multicolumn{3}{|c|}{......... kg/ha ........... } & & \multicolumn{3}{|c|}{........... kg/ha .......... } & tha \\
\hline 0 & 0 & 0 & - & 40 & $\mathbf{0}$ & $\mathbf{0}$ & $114 \mathrm{c}$ \\
\hline 0 & 0 & 0 & 2042 & 40 & 0 & $\mathbf{0}$ & $115 \mathrm{c}$ \\
\hline 0 & 42 & 30 & 1553 & 40 & 0 & 0 & $114 \mathrm{c}$ \\
\hline 0 & 84 & 60 & 1733 & 40 & 0 & $\mathbf{0}$ & $115 \mathrm{c}$ \\
\hline 0 & 126 & 90 & 1684 & 40 & $\mathbf{0}$ & 0 & $113 \mathrm{c}$ \\
\hline 0 & 168 & 120 & 1783 & 40 & 0 & 0 & $129 \mathrm{ab}$ \\
\hline $\mathbf{0}$ & 210 & 150 & 1751 & 40 & $\mathbf{0}$ & $\mathbf{0}$ & $118 \mathrm{bc}$ \\
\hline $\mathbf{0}$ & $\mathbf{0}$ & $\mathbf{0}$ & - & 56 & 80 & 80 & $132 \mathrm{a}$ \\
\hline 0 & 0 & 0 & 1885 & 56 & 80 & 80 & $135 \mathrm{a}$ \\
\hline 0 & 42 & 30 & 1828 & 56 & 80 & 80 & $136 \mathrm{a}$ \\
\hline 0 & 84 & 60 & 1803 & 56 & 80 & 80 & $138 \mathrm{a}$ \\
\hline 0 & 126 & 90 & 1702 & 56 & 80 & 80 & $138 \mathrm{a}$ \\
\hline 0 & 168 & 120 & 1595 & 56 & 80 & 80 & $130 \mathrm{ab}$ \\
\hline 0 & 210 & 150 & 1896 & 56 & 80 & 80 & $134 \mathrm{a}$ \\
\hline CV\% & & & 19,7 & & & & 5,5 \\
\hline Teste F & & & ns & & & & * \\
\hline
\end{tabular}

Medias seguidas pela mesma letra não diferem significativamente pelo teste de Duncan a $5 \%$. 
TABELA 2 - Teores de N, P, K, Ca e Mg nas folhas de soja na época de florescimento em função das adubações da soja.

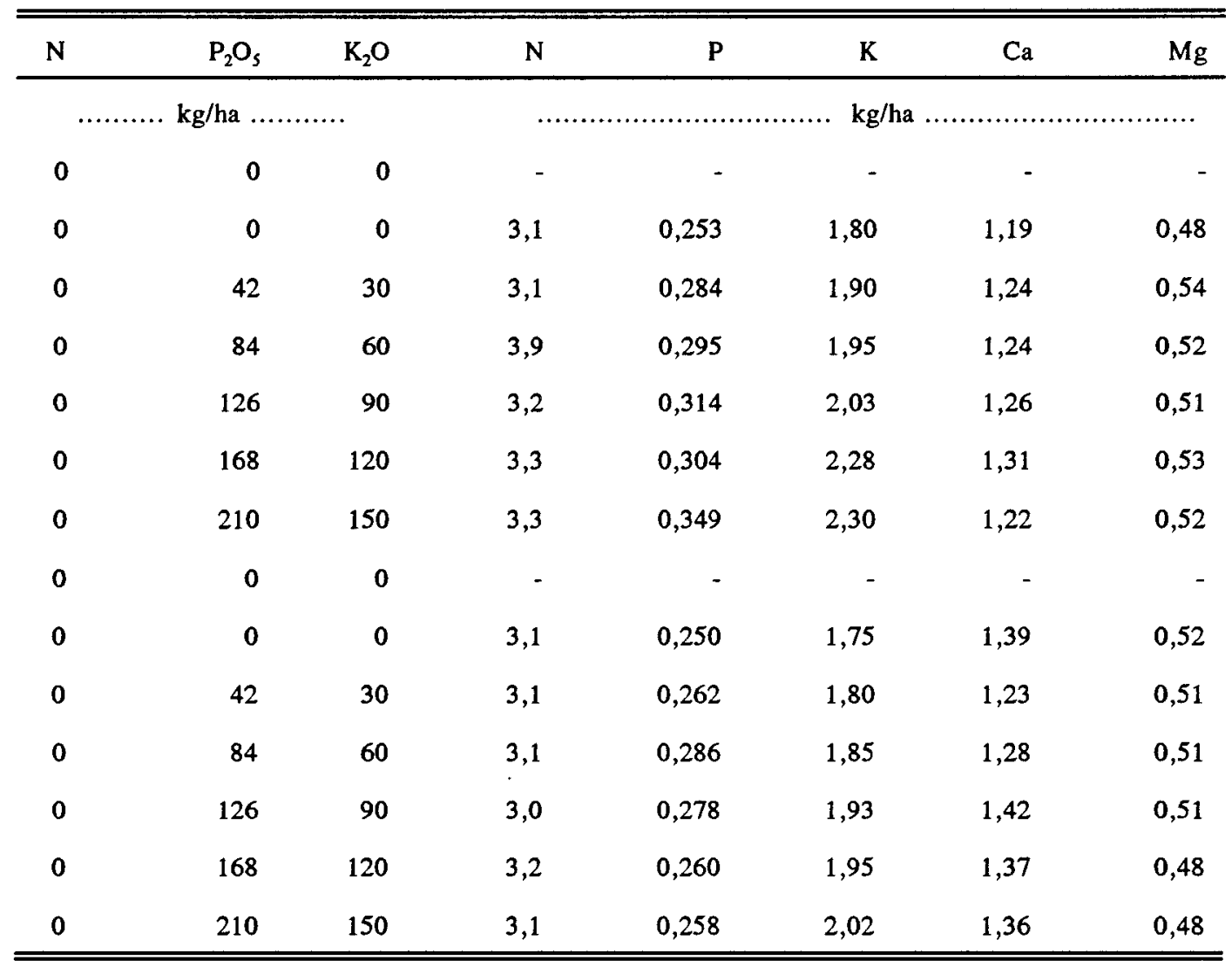

Além disso, o cultivar de soja IACFoscarin-31 é tolerante à alta disponibilidade de manganês (MASCARENHAS et al., 1990) e menos exigente em fósforo e potássio (TANAKA \& MASCARENHAS, 1992) do que os outros cultivares. Os tratamentos com adubos aumentaram as concentrações nas folhas sem aumentar a produtividade, indicando que houve uma absorção de luxo (TABELA 2).

Os dados de produtividade apresentados na TABELA 1 mostram que a cana de açúcar apenas aproveitou o efeito residual da adubação da soja, quando esta foi superior a $0-126-90 \mathrm{~kg} / \mathrm{ha}$. A produtividade média de $1700 \mathrm{~kg} / \mathrm{ha}$ de soja deve ter exportado somente $20 \mathrm{~kg} / \mathrm{ha} \mathrm{de} \mathrm{P}_{2} \mathrm{O}_{5}$ e $38 \mathrm{~kg} / \mathrm{ha}$ de
$\mathrm{K}_{2} \mathrm{O}$, deixando ainda uma considerável quantidade de nutrientes primários para a cana. Infere-se portanto que a cana para ter um desenvolvimento normal, necessita que o adubo seja aplicado de forma localizada, não tendo capacidade eficiente para aproveitar o resíduo das adubações anteriores. Os dois tratamentos de alqueive da soja evidenciaram que esta cultura não trouxe benefícios para a cana de açúcar, pois tanto com o alqueive como com a soja, as produtividades de cana foram semelhantes.

As folhas da cana não apresentaram variações em função dos cultivos anteriores de soja ou das adubações residuais da soja e diretas da cana de açúcar (TABELA 3). 
TABELA 3 - Teores de N, P, K, Ca e Mg nas folhas de cana-de-açúcar em função das adubações residuais e diretas, respectivamente da soja e da cana-de-açúcar.

\begin{tabular}{|c|c|c|c|c|c|c|c|c|c|c|}
\hline \multirow[b]{2}{*}{$\mathrm{N}$} & \multicolumn{2}{|c|}{ Soja } & \multicolumn{3}{|c|}{ Cana de Açúcar } & \multicolumn{5}{|c|}{ Cana de Açúcar } \\
\hline & $\mathrm{P}_{2} \mathrm{O}_{5}$ & $\mathrm{~K}_{2} \mathrm{O}$ & $\mathbf{N}$ & $\mathrm{P}_{2} \mathrm{O}_{5}$ & $\mathrm{~K}_{2} \mathrm{O}$ & $\mathbf{N}$ & $\mathbf{P}$ & $\mathbf{K}$ & $\mathrm{Ca}$ & $\mathrm{Mg}$ \\
\hline ...... & & $\ldots \ldots$ & $a$. & $\cdots$ & $\cdots$ & $\ldots \ldots$ & & $\%$ & ........ & $\ldots \ldots$ \\
\hline 0 & 0 & 0 & 40 & 0 & 0 & 2,28 & 0,165 & 1,70 & 0,34 & 0,14 \\
\hline 0 & 0 & 0 & 40 & 0 & 0 & 2,31 & 0,162 & 1,70 & 0,33 & 0,14 \\
\hline 0 & 42 & 30 & 40 & 0 & 0 & 2,34 & 0,150 & 1,60 & 0,36 & 0,15 \\
\hline 0 & 84 & 60 & 40 & 0 & 0 & 2,32 & 0,157 & 1,50 & 0,35 & 0,15 \\
\hline 0 & 126 & 90 & 40 & 0 & 0 & 2,30 & 0,161 & 1,70 & 0,38 & 0,15 \\
\hline 0 & 168 & 120 & 40 & 0 & 0 & 2,34 & 0,168 & 1,60 & 0,35 & 0,15 \\
\hline 0 & 210 & 150 & 40 & 0 & 0 & 2,23 & 0,173 & 1,70 & 0,33 & 0,15 \\
\hline 0 & 0 & 0 & 56 & 80 & 80 & 2,27 & 0,156 & 1,70 & 0,35 & 0,14 \\
\hline 0 & 0 & 0 & 56 & 80 & 80 & 2,27 & 0,163 & 1,70 & 0,36 & 0,15 \\
\hline 0 & 42 & 30 & 56 & 80 & 80 & 2,33 & 0,171 & 1,70 & 0,37 & 0,15 \\
\hline 0 & 84 & 60 & 56 & 80 & 80 & 2,38 & 0,167 & 1,70 & 0,37 & 0,15 \\
\hline 0 & 126 & 90 & 56 & 80 & 80 & 2,44 & 0,166 & 1,70 & 0,38 & 0,15 \\
\hline 0 & 168 & 120 & 56 & 80 & 80 & 2,35 & 0,166 & 1,70 & 0,39 & 0,15 \\
\hline 0 & 210 & 150 & 56 & 80 & 80 & 2,29 & 0,168 & 1,80 & 0,36 & 0,14 \\
\hline
\end{tabular}

\section{REFERÊNCIAS BIBLIOGRÁFICAS}

ARRUDA, F.B.; MASCARENHAS, H.A.A.; VIEIRA, S.R. Efeito hídrico na produção de soja. Campinas, Instituto Agronômico, 1976. 23p. (Boletim Técnico, 38).

BATAGLIA, O.C.; MASCARENHAS, H.A.A.; TISSELLI FILHO, O. Composição mineral das sementes de nove cultivares de soja. Bragantia, Campinas, v.36, p.XLVIII-L, 1977.

BATAGLIA, O.C.; FURLANI, A.M.C.; TEDXEIRA, J.P.F.; FURLANI, P.R.; GALLO, J.R. Métodos de análise química de plantas. Campinas: Instituto Agronômico, Campinas, 1983.41p. (Boletim Técnico, 78).
ESPIRONELO, A.; COSTA, A.A.; LANDELL, M.G. de A; PEREIRA, J.C.V.A.; IGUE, T; CAMARGO, A.P.; RAMOS, M.T.B. Adubaçāo em três variedades de cana-de-açúcar em função de dois espaçamentos. Bragantia, Campinas, v.46, n.2, p.247-268, 1987.

MASCARENHAS, H.A.A.; BULISANI, E.A.; BRAGA, N.R. Rotação de culturas. In: SIMPÓSIO SOBRE SISTEMAS DE PRODUÇÃO AGRICOLA, Campinas, 1984. Campinas: Fundação Cargill, 1984. p.87-112.

MASCARENHAS, H.A.A.; MIRANDA, M.A.C. de; TANAKA, R.T.; FALIVENE, S.M.P.; DECHEN, A.R. Comportamento de cultivares precoces de soja em solução nutritiva contendo diferentes níveis de manganês. Pesquisa Agropecuária Brasileira, Brasilia, v.25, n.4, p.609-615, 1990. 
MASCARENHAS, H.A.A.; HIROCE, R.; BRAGA, N.R.; MIRANDA, M.A.C. de; POMMER, C.V.; SAWASAKI, E. Nitrogénio residual soja-milho. Campinas, Instituto Agronômico, 1977. 16p. (Boletim Técnico, 58).

MIYASAKA, S. Economia de energia na adubação de culturas: uso de resíduos orgânicos. Campinas, Instituto Agronómico, 1983. 47p.

OHLROGGE, A.J.; KAMPRATH, E.J. Fertilizer use in soybeans. In DINAUR, R.C. (Ed.). Changing patterns in fertilizer use. Madison, Soil Science Society of America, 1968. p.273-295.
PRIMAVESI, A. O manejo ecológico do solo: a agricultura em regiōes tropicais. 4.ed., São Paulo, Nobel, 1982. 541p.

ROHWEDER, D.A.; SHRADER, W.J.; TEMPLETON, W.C. Legumes. Crops and Soils, Madison, v.9, n.6, p.11-14, 1977.

TANAKA, R.T.; MASCARENHAS, H.A.A. Soja: nutrição, correção do solo e adubação. Campinas: Fundação Cargill, 1992.60p. (Serie Técnica, 7).

Enviado para publicação em 30.08 .93 Aceito para publicação em 24.01 .94 